\section{Influence of Citrullus lanatus var. citroides Rootstocks and Their F1 Hybrids on Yield and Response to Root- knot Nematode, Meloidogyne incognita, in Grafted Watermelon}

\author{
Judy A. Thies ${ }^{1}$, Sharon Buckner, and Matthew Horry \\ U.S. Vegetable Laboratory, USDA, ARS, 2700 Savannah Highway, \\ Charleston, SC 29414
}

\author{
Richard Hassell \\ Clemson University, Coastal Research and Education Center, 2700 \\ Savannah Highway, Charleston, SC 29414 \\ Amnon Levi \\ U.S. Vegetable Laboratory, USDA, ARS, 2700 Savannah Highway, Charleston, \\ SC 29414
}

Additional index words. hybrid watermelon rootstocks, root-knot nematode resistance, grafting

\begin{abstract}
Southern root-knot nematodes (Meloidogyne incognita) are an important reemerging pest of watermelon in the United States and worldwide. The re-emergence of root-knot nematodes (RKNs) in watermelon and other cucurbits is largely the result of the intensive cultivation of vegetable crops on limited agricultural lands coupled with the loss of methyl bromide for pre-plant soil fumigation, which has been the primary method for control of RKNs and many soilborne diseases of cucurbits and other vegetable crops for several decades. One alternative for managing $R K N$ in watermelon is the use of resistant rootstocks for grafted watermelon. We have developed several RKN-resistant Citrullus lanatus var. citroides lines (designated RKVL for Root-Knot Vegetable Laboratory), which have shown promise as rootstocks for grafted watermelon. In 2011 and 2012, we demonstrated that $F 1$ hybrids derived from our selected RKVL lines exhibited resistance to RKN that was equal to or greater than that of the parental RKVL lines when grown in fields highly infested with $M$. incognita. In 2011, although significant differences were not observed among rootstocks, the F1 hybrids produced slightly higher yields compared with the selected parental lines. Among the selected parental lines, RKVL 318 produced high yields in both years. In 2011, three of four RKVL parental lines and all four of their $F 1$ hybrids produced greater $(P<0.05)$ fruit yields than self-grafted 'Tri-X 313', 'Emphasis' bottle gourd, and 'Strong Tosa' squash hybrid. In 2012, three RKVL F1 hybrid lines produced higher yields than the selected parents. Overall, these F1 hybrids were vigorous and should provide useful genetic material for selection and development of robust RKN-resistant C. lanatus var. citroides rootstock lines.
\end{abstract}

As a result of intensive cultivation of vegetable crops on limited land resources, soilborne diseases and pests of vegetable crops have significantly increased in recent years, particularly after the removal of the soil fumigant methyl bromide from the market in accordance with the Montreal Protocol on Substances that Deplete the Ozone Layer and the U.S. Clean Air Act (U.S. Environmental Protection Agency, 2012). Presently,

Received for publication 1 Oct. 2013. Accepted for publication 11 Nov. 2013.

Mention of a trademark name or proprietary product does not constitute a warranty or guarantee by the U.S. Department of Agriculture nor does it imply exclusion of other products that may also be suitable. ${ }^{1}$ To whom reprint requests should be addressed; e-mail Judy.Thies@comcast.net.
ARS maintains 134 U.S. PIs of the wild-type watermelon Citrullus lanatus var. citroides collected in Africa, which is considered the possible center of origin of watermelon (Jarret et al., 1997). In previous studies, we identified a considerable number of C. lanatus var. citroides PIs that show resistance to RKNs (Thies and Levi, 2003, 2007). Several of these resistant PIs were selected and self-pollinated in three successive generations to obtain pure line selections. These lines (which we have designated RKVL) have proved to be vigorous rootstocks, producing significantly higher watermelon yield than the commercially available cucurbit rootstocks in fields infested with RKNs (Thies et al., 2010).

$\mathrm{F}_{1}$ hybrid rootstocks have proved useful in different crops, including the Cucurbita maxima $\times C$. moschata hybrid rootstock used for grafting melon, cucumber, and watermelons. Most of the watermelons grown in the Mediterranean basin are grafted on F1 hybrids of Cucurbita rootstocks (Yetisir et al., 2003). The wide genetic diversity that exists among the $C$. lanatus var. citroides accessions might be useful for generating heterotic F1 hybrid rootstocks, resistant to RKNs, and possibly to other soilborne diseases of watermelon (Levi et al., 2012).

Our overall goal is to develop heterotic F1 hybrid lines of RKVL that produce higher yields and have increased disease and pest resistances (Thies et al., 2012). In this study, we examined the responses of our selected RKVL lines and their F1 hybrids as rootstocks for grafted watermelon in fields infested with RKNs.

\section{Materials and Methods}

Expt. 1: Charleston, SC, 2011. The experiment was conducted in an $M$. incognitainfested field at the U.S. Vegetable Laboratory in Charleston, SC. Seeds of watermelon scion 'Tri-X 313' plants and rootstock plants were sown in 72 cell trays (TLC Polyform, Inc., Minneapolis, MN) on 19 May 2011. Ten days later, 'Tri-X 313' watermelon scions were grafted on to each of the rootstocks using the single cotyledon method (Hassell, 2007). On 15 June 2011, grafted plants were transplanted into single-row plots on raised white plastic mulch beds on $6.1-\mathrm{m}$ centers. The experimental design was a randomized complete block with six replications and each plot consisted of a single row of six watermelon plants with plants spaced $0.9 \mathrm{~m}$ apart. Four elite rootstock lines (designated RKVL) of C. lanatus var. citroides and four F1 hybrids of these lines (developed at the U.S. Vegetable Laboratory, USDA, ARS in Charleston, SC) were selected for use in the experiment. Commercial rootstocks also included in the study were 'Emphasis' Lagenaria siceraria, 'Ojakkyo' C. lanatus var. citroides, 'Strong Tosa' Cucurbita maxima $\times$ Cucurbita moschata hybrid, and self-grafted and non-grafted seedless watermelon 'Tri-X 313' C. lanatus var. lanatus. Fruits were harvested and fruit weights recorded six times from 8 Aug. through 31 
Aug. On 2 Sept., shoots of all plants were clipped and roots were lifted from soil and washed. Root systems of each plant were stained using the method of Thies et al. (2002) and evaluated for severity of galling and egg mass production. Percentages of root system galled or covered in egg masses were recorded for each plant. Root systems from each plot were bulked, weighed, cut into 1 - to $2-\mathrm{cm}$ pieces, and eggs were extracted using 1.0\% $\mathrm{NaOCl}$ (Hussey and Barker, 1973). Eggs were counted using a stereomicroscope. Eggs per gram fresh root were $\log ^{10}(\mathrm{x}+1)$ transformed for analysis of variance (ANOVA) to normalize data. Analysis of variance was conducted using the GLM procedure of SAS Version 9.1 for Windows (SAS Institute Inc., Cary, $\mathrm{NC)}$ and means were separated using Fisher's protected least significant difference (LSD).

Expt. 2: Charleston, SC, 2012. The experiment was conducted in Charleston, $\mathrm{SC}$, at the same field site as in 2011 and experimental methods were the same as those previously described for the 2011 experiment. Seeds of watermelon scion 'Tri-X 313' plants and rootstock plants were sown on 22 Mar. 2012. 'Tri-X 313' watermelon scions were grafted on to each of the rootstocks $10 \mathrm{~d}$ later. Plots were laid out as in 2011 and grafted plants were transplanted into the field on 1 June. The experimental design was a randomized complete block design with six replicates. Fruits were harvested and fruit weights recorded eight times from 2 Aug. through 23 Aug. On 29 Aug., shoots of all plants were clipped and roots were lifted from soil and washed. Percentages of root galling and egg masses present on the roots and percentages of root systems with fibrous roots were recorded. Eggs of $M$. incognita were extracted from roots and counted as described for the 2011 experiment. Eggs per gram fresh root were $\log ^{10}(\mathrm{x}+1)$ transformed for ANOVA to normalize the data.
Data were analyzed using the GLM procedure of SAS and means were separated by Fisher's protected LSD.

\section{Results and Discussion}

The first objective of these studies, conducted in both 2011 and 2012, was to examine whether F1 hybrids derived from our selected RKN-resistant RKVL lines (Thies et al., 2010, 2012) exhibited resistance in fields highly infested with this soilborne pest. In 2011, there were no significant differences among the selected parental RKVL lines and their F1 hybrids for the percentages of root systems with galls and egg masses present (Table 1). Percentages of root systems with galls and egg masses ranged from 4.9 to 12.4 and 0.9 to 3.6, respectively, for the selected parental RKVL lines. In comparison, the four F1 hybrid RKVL lines had percentages of root systems galled ranging from 9.8 to 14.8 and percentages of root systems with egg masses ranging from 3.3 to 6.6. Root systems of 'Tri-X 313' non-grafted and 'Tri-X 313' self-grafted had $14.6 \%$ and $11.0 \%$, respectively, and $2.7 \%$ and $2.6 \%$ egg mass production. All RKVL lines and their F1 hybrids had significantly lower $(P<0.05)$ percentages of root galling and egg mass production than the squash hybrid rootstock 'Strong Tosa' $(92.0 \%$ and $86.3 \%$, respectively) and the bottle gourd rootstock 'Emphasis' (78.2\% and 51.4\%, respectively) (Table 1; Fig. 1). All but one of each of the RKVL parental lines and their F1 hybrids (RKVL 317 and RKVL $318 \times 301)$ had significantly lower numbers $(P<0.05)$ of eggs per gram fresh root (range five to 24) than 'Tri-X 313' non-grafted (41) and 'Tri-X 313' self-grafted (34). F1 hybrids had lower $(P<$ $0.05)$ numbers of eggs per gram fresh root than the commercial rootstocks 'Emphasis' bottle gourd (1114) and 'Strong Tosa' squash hybrid (2653) (Table 1).

In 2012, percentages of root systems with galls and egg masses ranged from
6.6 to 21.2 and 0.4 to 2.1 , respectively, for the RKVL parental lines (Table 2). In comparison, the nine F1 hybrid RKVL lines had percentages of root systems galled ranging from 2.0 to 16.0 and percentages of root systems with egg masses ranging from 0.3 to 1.4. Root systems of all but one of the parental (RKVL 317) had lower $(P<0.05)$ percentages galling than non-grafted 'Tri-X $313^{\prime}$ (32.0\%). The parental line RKVL 317 had a greater $(P<0.05)$ percentage of galling $(21.2 \%)$ than self-grafted 'Tri313 ' (16.2\%); otherwise no differences were observed between self-grafted ' $T r i-X$ 313' and the parental and F1 hybrid RKVL lines for percentages root galling. All RKVL lines, except RKVL 317, and their F1 hybrids had significantly lower $(P<$ $0.05)$ percentages of root galling and egg mass production than the squash hybrid rootstock 'Strong Tosa' (89.9\% and $34.9 \%$, respectively) and the bottle gourd rootstock 'Emphasis' (73.9\% and 35.0\%, respectively) (Table 2). In recent studies in fields naturally infested with RKNs in Charleston, SC, and Quincy, FL, the same commercial cucurbit rootstocks were highly infected with RKNs, whereas selected RKVL lines had overall low root galling and high percentages of root systems with fibrous roots (Thies et al., 2009, 2010). In the 2012 study, numbers of eggs per gram fresh root for the RKVL parental lines did not differ significantly from each other (range 42 to 260) (Table 2). The F1 hybrid lines had numbers of eggs per gram fresh root ranging from 14 to 625 . Three of the F1 hybrid lines (RKVL $316 \times$ RKVL 318, RKVL $317 \times$ RKVL 318, and RKVL 318 $\times$ RKVL 317$)$ had lower $(P<0.05)$ numbers of eggs per gram fresh root $(24,41$, and 14 , respectively) than the parental line RKVL 318 (260) and the F1 hybrid RKVL $316 \times$ RKVL 317 (148). Percentages of fibrous roots were greater $(P<0.05)$ for all of the RKVL parental lines and their F1 hybrids

Table 1. Percentage of root system galled and covered with egg masses of Meloidogyne incognita, numbers of M. incognita eggs per gram fresh root, and total fruit yield for 'Tri-X 313' seedless watermelon grafted on rootstocks of Citrullus lanatus var. citroides hybrid and parental lines, Lagenaria siceraria, Cucurbita moschata $\times$ C. maxima, and self-grafted and non-grafted 'Tri-X 313', Charleston, SC, 2011 field study.

\begin{tabular}{|c|c|c|c|c|c|}
\hline \multirow[b]{2}{*}{ Rootstock entry } & \multirow{2}{*}{$\begin{array}{l}\text { Percentage root } \\
\text { system galled }\end{array}$} & \multirow{2}{*}{$\begin{array}{l}\text { Percentage root system } \\
\text { covered with egg masses }\end{array}$} & \multicolumn{2}{|c|}{ No. eggs/fresh root } & \multirow{2}{*}{$\begin{array}{c}\text { Total yield } \\
\text { (kg/plot) }\end{array}$} \\
\hline & & & $\left(\log _{10} \text { transformed }\right)^{z}$ & $\overline{\text { (untransformed) }}$ & \\
\hline RKVL 301 & $4.8 \mathrm{~b}^{\mathrm{y}}$ & $0.9 \mathrm{a}$ & $0.008 \mathrm{ab}$ & (5) & $21.61 \mathrm{a}$ \\
\hline RKVL 318 & $4.7 \mathrm{~b}$ & $3.1 \mathrm{a}$ & $0.006 \mathrm{a}$ & (5) & $45.10 \mathrm{c}$ \\
\hline RKVL $301 \times 316$ & $9.8 \mathrm{~b}$ & $3.3 \mathrm{a}$ & $0.008 \mathrm{ab}$ & (5) & $46.26 \mathrm{c}$ \\
\hline RKVL $301 \times 318$ & $14.5 \mathrm{~b}$ & $6.6 \mathrm{a}$ & $0.008 \mathrm{ab}$ & (5) & $42.18 \mathrm{bc}$ \\
\hline Ojakkyo & $6.0 \mathrm{~b}$ & $3.0 \mathrm{a}$ & $0.008 \mathrm{ab}$ & (7) & $49.61 \mathrm{c}$ \\
\hline \multicolumn{6}{|l|}{ Lagenaria sicereria } \\
\hline Emphasis & $78.2 \mathrm{c}$ & $51.4 \mathrm{~b}$ & $0.0365 \mathrm{~d}$ & $(1,114)$ & $35.66 \mathrm{a}$ \\
\hline \multicolumn{6}{|l|}{ C. lanatus var. lanatus } \\
\hline Tri-X 313 NG & $14.6 \mathrm{~b}$ & $2.7 \mathrm{a}$ & $0.019 \mathrm{c}$ & (41) & $43.49 \mathrm{c}$ \\
\hline Tri-X 313 SG & $11.0 \mathrm{~b}$ & $2.6 \mathrm{a}$ & $0.017 \mathrm{c}$ & (34) & $37.06 \mathrm{a}$ \\
\hline \multicolumn{6}{|c|}{ Cucurbita maxima $\times$ C. moschata } \\
\hline
\end{tabular}

${ }^{\mathrm{z}}$ Data were $\log _{10}(\mathrm{x}+1)$ transformed before analysis. Nontransformed data are shown in parentheses.

${ }^{y}$ Means within a column followed by the same letter are nonsignificantly different $(P<0.05)$ according to Fisher's protected least significant difference.

$\mathrm{NG}=$ non-grafted; $\mathrm{SG}=$ self-grafted. 


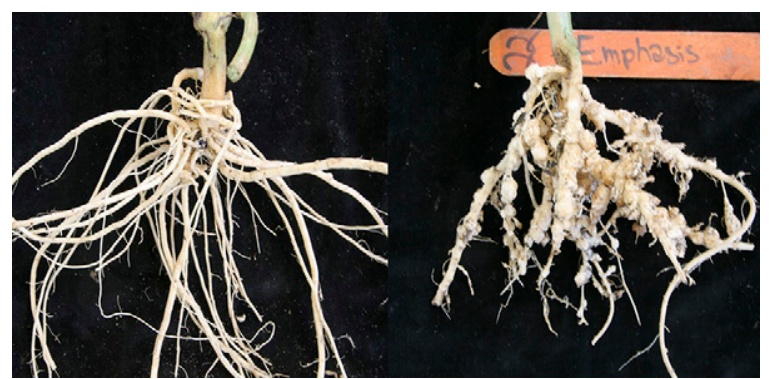

Fig. 1. Root-knot nematode (RKN)-resistant F1 hybrid RKVL $301 \times 318$ watermelon root system with very minimal RKN galling and very fibrous root system (left); RKN-susceptible 'Emphasis' bottle gourd root system with severe RKN galling (right). Sept. 2011, Charleston, SC. with the RKVL parental and F1 hybrid lines (Tables 1 and 2).

Overall, the RKVL parental lines and their F1 hybrids were highly compatible rootstocks for grafted 'Tri-X 313' triploid seedless watermelon. Our goal is to continue exploring and expanding the C. lanatus var. citroides germplasm collection and to identify accessions with wide genetic diversity that might be useful for the development of improved C. lanatus var. citroides hybrid rootstocks that could improve performance for grafted watermelons and provide an alternative for methyl bromide fumigation.

Table 2. Percentage of root system galled and covered with egg masses of Meloidogyne incognita, percentage of root system with fibrous roots, numbers of M. incognita eggs per gram fresh root, and total fruit yield for 'Tri-X 313' seedless watermelon grafted on rootstocks of C. lanatus var. citroides hybrid and parental lines, Lagenaria siceraria, Cucurbita moschata $\times$ C. maxima, and self-grafted and non-grafted 'Tri-X 313', Charleston, SC, 2012 field study.

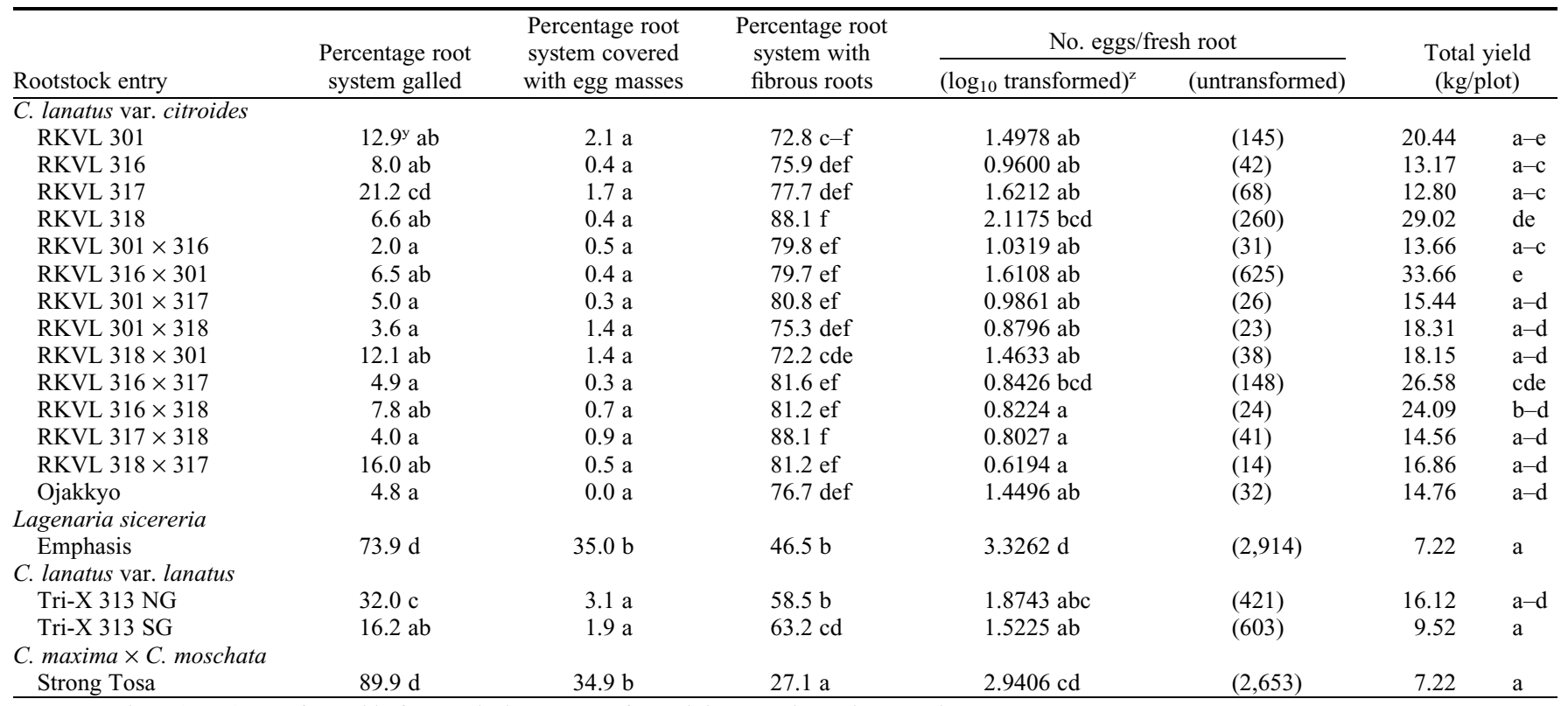

${ }^{2}$ Data were $\log _{10}(x+1)$ transformed before analysis. Nontransformed data are shown in parentheses.

y Means within a column followed by the same letter are nonsignificantly different $(P<0.05)$ according to Fisher's protected least significant difference.

$\mathrm{NG}=$ non-grafted; $\mathrm{SG}=$ self-grafted.

(range $72.2 \%$ to $88.1 \%$ ) than non-grafted 'Tri-X 313' (58.5\%), 'Emphasis' bottle gourd $(46.5 \%)$, and 'Strong Tosa' squash hybrid $(27.1 \%)$. The parental line RKVL 318 and seven of nine F1 hybrids (range $79.7 \%$ to $88.1 \%)$ had greater $(P<0.05)$ percentages of fibrous roots than self-grafted 'Tri-313' (63.2\%). In previous studies, we have observed that fibrous root production by $C$. lanatus var. citroides accessions and breeding lines was associated with resistance to RKNs (Thies et al., 2010). Therefore, we use percentage fibrous roots as an additional trait for identifying $\mathrm{RKN}$ resistance in C. lanatus var. citroides (Fig. 1).

The second objective of these studies was to examine whether any of the F1 hybrids derived from our selected RKVL lines produce high yields for grafted watermelon in RKN-infested fields. Among the selected parental lines, RKVL 318 produced high yields in both years (Tables 1 and 2). The results in the 2011 experiment show that although there were no significant differences among rootstocks, the $\mathrm{F} 1$ hybrids produced slightly higher yields ( 42.18 to $53.93 \mathrm{~kg}$ per plot) than the RKVL parental lines (21.61 to $46.13 \mathrm{~kg}$ per plot) (Table 1). Two of four RKVL parental lines and all four of their F1 hybrids produced greater $(P<0.05)$ fruit yields (range 42.18 to $53.93 \mathrm{~kg} / \mathrm{plot}$ ) than self-grafted 'Tri-X 313' (37.06 $\mathrm{kg} / \mathrm{plot}$ ), 'Emphasis' bottle gourd (35.66 $\mathrm{kg} / \mathrm{plot}$ ) and 'Strong Tosa' squash hybrid $(23.67 \mathrm{~kg} / \mathrm{plot})$

In 2012, the F1 hybrids RKVL $316 \times$ RKVL 301, RKVL $316 \times 317$, and RKVL $316 \times 318$ produced significantly higher $(P<$ $0.05)$ yields than self-grafted 'Tri-X 313' (Table 2). Overall, these F1 hybrids were vigorous and should be useful as hybrid rootstocks for grafted watermelon and as genetic material for selecting and further developing robust $C$. lanatus var. citroides rootstock lines. Like in our previous studies, the commercial cucurbit rootstock lines were highly susceptible to RKN and produced significantly lower watermelon yields compared

\section{Literature Cited}

Hassell, R. 2007. Grafting methods and procedures involved in producing quality transplants. HortScience 42:802 (abstract).

Hussey, R.S. and K.R. Barker. 1973. A comparison of methods of collecting inocula of Meloidogyne spp., including a new technique. Plant Dis. Rpt. 57:1025-1028.

Jarret, R.L., L.C. Merrick, T. Holms, J. Evans, and M.K. Aradhya. 1997. Simple sequence repeats in watermelon [Citrullus lanatus (Thunb.) Matsum. \& Nakai]. Genome 40:433-441.

Levi, A., J. A. Thies, W. P. Wechter, H. F. Harrison Jr., A. M. Simmons, U. Reddy, P. Nimmakayala, and Z. Fei. 2012. High frequency oligonucleotidesTargeting active gene (HFO-TAG) markers reveal wide genetic diversity among Citrullus spp. accessions useful for enhancing disease or pest resistance in watermelon cultivars. Genet. Resources Crop Evol. 60:427-440.

Lynch, L. and J. Carpenter. 1999. The economic impacts of banning methyl bromide: Where do we need more research? 1999 Annual Research Conference on Methyl Bromide Alternatives and Emissions Reductions. 31 Oct. 2014 $<$ http://mbao.org/1999airc/55lynchl.pdf $>$. 
Thies, J.A., J. Ariss, R.L. Hassell, and A. Levi. 2012. Root-knot nematode resistant rootstocks for grafted watermelon. Acta Hort. 201-211.

Thies, J.A., J.J. Ariss, R.L. Hassell, S. Olsen, C.S. Kousik, and A. Levi. 2010. Grafting for management of southern root-knot nematode, Meloidogyne incognita, in watermelon. Plant Dis. 94:1195-1199.

Thies, J.A. and A. Levi. 2003. Resistance of watermelon germplasm to the peanut root-knot nematode. HortScience 38:14171421.

Thies, J.A. and A. Levi. 2007. Characterization of watermelon (Citrullus lanatus var. citroides) germplasm for resistance to root-knot nematodes. HortScience 42:1530-1533.

Thies, J.A., S.B. Merrill, and E. Luther Corley. 2002. Red food coloring stain: New, safer procedures for staining nematodes in roots and egg masses on root surfaces. J. Nematol. 34:179-181.

U.S. Environmental Protection Agency. 2012. Ozone layer protection. 3 Nov. 2014. <http:// www.epa.gov/ozone/intpol/index.html>.

Yetisir, H., N. Sari, and S. Yucel. 2003. Rootstock resistance to fusarium wilt and effect on watermelon fruit yield and quality. Phytoparasitica 31:163-169. 